\title{
The Cultural Connotation and Symbolic Meaning of Chinese Opera Mask Color
}

\author{
Hanbing Tu \\ Jilin Agricultural University \\ Jilin, China
}

\begin{abstract}
Color is an important part of Chinese opera mask. It not only conveys Chinese unique custom of color and cultural connotation through color line and color block, but also endows the opera mask art with rich symbolic meaning and aesthetic significance. Taking the colors of Chinese opera mask as research object, the paper has studied the cultural connotation in Chinese opera mask color, analyzed and expounded the symbolic meaning and aesthetic significance in Chinese opera mask color.
\end{abstract}

Keywords-opera mask; cultural connotation; symbolic meaning; aesthetic meaning

\section{INTRODUCTION}

Chinese opera has a unique position on the world stage. With unique design and mask colors, it contains extensive and profound culture. In its glorious history, the traditional opera of Han people is specific and different from the makeup art of other countries. The author will talk about Chinese opera mask from several aspects.

\section{The Cultural CONNOTATION CONVEYED BY THE COLOR OF CHINESE TRADITIONAL OPERAS}

We can clearly see the mark of our traditional culture through the color composition of Chinese opera mask. It was the worship of totem and sacrificial rites in ancient times that formed the love of natural color in opera mask. The culture of yin-yang and five elements and the harmony of nature and man form the taboo of five colors, which gradually becomes a significant standard and example in coloring of opera mask and mask color aesthetics. Combining with the harmony of nature and man, the colors of opera mask can tell the role of opera. Influenced by the national tradition and regional aesthetic culture, the love of natural colors, coloring and aesthetic standards gradually transformed into a custom, and even a fixed mode, and was handed down. Therefore, Chinese traditional culture gives an important impetus and influence on the formation of opera mask color.

\section{A. The Culture of the Worship of Totem and Sacrificial Rites}

The worship of totem and sacrificial rites are the earliest culture of human. The love of natural color came from this culture, which drove the formation of Chinese opera mask color. The earliest aesthetic consciousness on color originated from human's living environment. Man began to worship and fear natural power in the contact of nature, and regarded some natural colors as protection color and some as taboo color in the tribe. The most ancient color system was used in the sacrificial rite. As the origin of Chinese opera, the selection and application of colors of dress-up activities in the sacrificial rite have produced an unignorable referential value and influence on the formation of Chinese opera mask color. In the tribal period, cold and hunger were key words in the life of people. At this time, people longed for warm spring and harvest autumn. "Green" and "red" were deeply loved and worshiped by people, because they made people think of spring and autumn. And these two colors became important part of mask. In earliest sacrificial rite, dress-up performance mainly included animal animation and god animation. Among them, the animal animation performance was direct animation of adoring animals. The animating objects included the movement and the colors of adoring animals. The selection of these colors strictly followed the worship color and taboo color in the tribal culture. The animation of adoring animals also showed people's perceptual knowledge of adoring things. The difference of god animation and animal animation lies in that gods don't really exist, so people finished their animation of gods with imagination. No matter in animation of animals or gods, the dress-up and masks used became an important standard and reference for later selection and application of opera mask color. Especially the selection of color in sacrificial rite, the love of natural color, and the dress-up with natural color and processed natural color provide the most primitive and the most direct reference for opera mask in the design and formation of "goblin" and "gods".

\section{B. The Culture of Yin-and-Yang and Five Elements and the Harmony between Man and Nature}

The culture of yin-yang and five elements and the harmony of man and nature is an important part of China's ancient culture. Under the combined action of the two, traditional fivecolor view has become important rules in the selection and application of color in Chinese opera mask. And it endows color of opera mask with rich symbolic meaning. In Chinese traditional habit and cultural life, the theory of the five elements and the universe view are important foundation in the formation of worship color and taboo color. Round heaven and square earth is the universe view of ancient Chinese. There are five directions, including east, west, south, north and centre. They separately belong to metal, wood, water, fire and earth. The colors of the five natural substances respectively are green, red, white, black and yellow, so the five colors are regarded as 
original color, and the other colors are secondary color. The original colors mix and form secondary color, such as bright pink, dark brown and bright green. The knowledge of people on these colors at that time came into being under very limited scientific condition, but the traditional five-color view is people's common knowledge. In the application of opera mask color, the five-color view is also one standard for the destiny of worship color and taboo color. For example, in the Ming Dynasty and Qing Dynasty, there were white, black and red in the role of Dajing. The positive roles generally have black or red face, and seldom use intermediate color. Using pure color to make up the face of positive roles became one tradition in the selection of opera mask color. On the other hand, the theory of five colors comes from the universe view, so it has become a symbol of the will of heaven. The symbol also stood for the destiny of a nation in the feudal period. Zou Yan of the Warring States period had put forward the theory of five-virtue circulation. He deemed that the conquering sequence of five elements was the changing basis of dynasty. Every dynasty has its worship colors and taboo colors. Different dynasty has different adoring colors, so the selection and application of color in Chinese opera mask also follows the mainstream color taboo and color aesthetics. Nowadays, the black mask in Chinese opera mainly represents a positive meaning. In the Yuan Dynasty, it used "black to make up the face" of the negative roles. This example shows that traditional five-color view is an important standard in the selection and application of color in Chinese opera mask, but it is not unalterable. It may develop with the development of the times.

The harmony of nature and man is one ancient Chinese philosophy. It affirms the intercommunity between man and nature, and emphasizes the unity of nature and man. It shows that nature or the Heaven is the same in nature, and requires people to realize the harmony between human and nature by adapting to the laws of nature. This philosophy is an important part of Confucianism. In the feudal society Confucianism was in a dominated position, so the philosophy of the harmony of nature and man is also included in opera mask field. People researched the existing laws between color and man and their intercommunity, and apply these color concepts in selection and application of opera mask color. Influenced by the philosophy, the color application in opera mask has the function to show character features and judge morality of characters. It makes the opera art colorful and gives opera mask a significant symbolic meaning.

\section{The Custom of Color under National Tradition and Regional Aesthetic Culture}

In different ethnic groups or different regions, we can find different national tradition and regional aesthetic culture through their application of opera mask color. National tradition and regional aesthetic culture are important cultural connotation conveyed in Chinese opera mask. Combined with opera mask, the aesthetic character of color becomes more prominent. And this aesthetic character is greatly influenced by the national tradition as well as the regional aesthetic habit. The influence of different national tradition is distinctly showed in the formation and selection of mask color. For example, Tibetan opera follows the color concept of Tibetan painting. It mainly uses red, white, black, yellow, green and blue colors, which is the same as Tibetan painting. The strong contrast and the use of bright colors are important characteristics in the application of Tibetan opera mask color. Different from other ethnic groups, colors of Tibetan opera mask can not only show symbolic meanings but also obvious religious meaning. For example, red stands for awesome. Generally use red mask for king. Monks dress up yellow robe. Immortals and Buddha wear yellow mask. In different cultural and ethnic background, the love and understanding of color are also different. The artistic expressions produced by the selection and application of different opera mask color can express national culture and the tendency of national aesthetics Therefore, the formation of opera mask color also has prominent national cultural characteristics.

As a unique form of makeup, the color application of Chinese opera mask also is naturally affected by the aesthetic habits of the audience. Due to different aesthetic orientations in different regions, the formation of the application of opera mask color shows different characteristics. Regional culture has an important influence on the development of opera mask color. The difference of regional aesthetic culture leads to the different formation of opera mask colors, which was obviously showed in the Ming Dynasty. For example, the role of Dajing of Kunshan opera and Geyang opera are differently performed. The red mask in Kunshan opera has many innovations, and the black mask in Geyang opera has prominent features. In Kunshan opera, Jia Sidao with white mask in Hongmei $J i$ and Yan Song in Fengming $J i$ are negative character. In Geyang opera, Bao Zheng in Timu Ji and Zhang Fei in Gucheng Ji with black mask are positive character with distinctive characters. The difference of white mask and black mask is influenced by the operas. And the regional tradition and aesthetic culture cannot be ignored in the formation of these differences. The red mask and white mask are also used in other operas just like Kunshan opera and Geyang opera, and they have the function of judging morality of characters. Maybe you would say it cannot explain the influence of regional custom and aesthetic culture on the formation of opera mask color. Then the difference of mask color between Qiyang opera and Qin opera can fully reflects the influence of south and north regional aesthetics on the formation of opera color. Qiyang people are simple and bold. This cultural environment endows Qiyang opera mask with special characteristics. It is with distinct coloring, rough and bold lines. The people of Northern Shaanxi are bold and unstrained. The full-bodied history and generous cultural atmosphere make the mask color of Qin opera concise and lively, with strong contrast. Grandeur is the most important aesthetic quality of Qin opera mask color. In short, different regions have different natural environments and histories, as well as aesthetic cultures. And the aesthetic culture plays an important role in composition of opera mask, and makes the selection and use of opera mask color with prominent regional characteristics.

\section{The SYMBolic MeANING OF CHINESE OPERA MASK COLOR}

The proper selection and application of Chinese opera mask color can hint the destiny or basic conditions of the role. 
For example, the frown of Bao Zheng shows his worry and hard thinking; the face of Xiang Yu with misery eyes shows his tragic fate; the role of Sun Wukong is painted with a monkey's face, which suggests that he is a monkey. Painting actor's face with colors distances audience from the plots of play. Actors with painted face look quite different. On one hand, it helps audience focus on the appreciation of opera itself. On the other hand, it can produce a sharp contrast when many actors with different color-painted faces come on stage at the same time. For example, "Junban" has a fine appearance, while "Dahualian" has an absurd face; when they come on stage at same time, there will be a strong contrast. The face of Jing always is painted with bright and heavy colors, and the accent of Jing is thick and rough, so as to form a unity of appearance and accent. It produces a strong artistic effect and increase the artistic expression of the opera itself.

In some cases, Chinese opera mask could show the skin color of the character by proper selection and application of colors. But its main purpose is to embody the personality of the character and judge the morality of the character. Take Beijing opera as an example. Red mask generally represents an upright and righteous person, such as Guan Yu and Huang Gai. Purple mask represents justice, strong and brave figures, such as Yang Yanzhao and Zhuan Zhu. Use black mask to shape upright and outspoken or reckless figures. The most representative figures are Bao Zheng, Li Kui and Zhang Fei. Use blue mask to shape obstinate and unruly and brave characters, such as, Dou Erdun and Liu Tang. The figures with yellow mask mainly are cruel but good at fighting, such as Yuwen Chengdu and Dian Wei. The figures with white mask generally are rude in manner, but tender in heart, such as Zhang Qing and Cheng Yaojin. In most cases, shape a god with gold or silver mask, such as Buddha and Bull Demon King, and shape a righteous old man with pink mask. Under the influence of habit and custom, color, as a special language, has its conventional meaning in opera. Therefore, the selection and application of Chinese opera mask color are not go-asyou-please. The realization of its symbolic meaning should take traditional custom as important basis. Although to portray the personality of opera character and judge the morality of character are important functions of Chinese opera mask color, the selection and application of opera mask color are not immutable and frozen. In different regions and operas, same color may shape different images. Even in same opera, opera mask color also may represent different images in different context. For example, in Beijing opera, red mask generally represents loyal and brave person. In Famen Temple, Liu Jin also is painted with a red face, and he is a negative person in the opera. But when you see his makeup of mouth, eyebrows and eyes, you could see his treacherous expression. $\mathrm{He}$ is a domineering eunuch. In this opera, red mask is used to show the high-fed life of Liu Jin. Here, red is an irony. In the Wild Boar Forest, Lu Zhishen is generous and brotherhood. He always helps others. Generally white mask represent treacherous character. In the opera, he is made up with a white face. It is because we also use white mask to shape a monk. Therefore, the symbolic meaning of Chinese opera mask color cannot be absolutely understood. In the study of Chinese opera mask color, the description of characters' personality and the function of judgment could only give a generally direction. In
Chinese opera, the use of opera mask color can mutually illustrate the image of opera role. Only by associating the image of opera character with mask color, can we decide the symbolic meaning of the role accurately.

\section{CONCLUSION}

Chinese opera masks reflect many aspects of our real life. Everyone can be a living actor who plays his role in the world stage. Everyone has his unique mask color, pattern style and personality. Opera mask gradually take shape with the maturity of opera, and fixes up. As a complete independent art style, it is an important of world culture. It fully reflects Chinese characteristics and represents China.

\section{REFERENCES}

[1] Zhong Yong. Red Face, Black Face, White Face, Ingot Face and Changing Face. Tianjin: Tianjin Social Science Publishing House, 2001.

[2] Luan Guanhua. Role Symbols - Chinese Opera Mask. Beijing: Sanlian Publishing House, 2005.

[3] Zheng Chuanyin. Traditional Culture and Classical Opera. Changsha: Hunan People's Publishing House, 2005.

[4] Li Mengming. Image Construction and Expression Experience of Opera Mask. Nankai Journal (PHILOSOPHY AND SOCIAL SCIENCES), 2001 (2). 